\title{
CONTAMINAÇÃO POR CHORUME E SUA DETECÇÃO POR RESISTIVIDADE
}

\author{
José Domingos Faraco Gallas ${ }^{1,2}$, Fabio Taioli², Sandra Márcia Cesário Pereira da Silva ${ }^{3}$, \\ Osmar Gustavo Wöhl Coelho ${ }^{1}$ e Paulo Sérgio Gomes Paim ${ }^{1}$
}

Recebido em 23 fevereiro, 2005 / Aceito em 13 maio, 2005 Received on February 23, 2005 / Accepted on May 13, 2005

\begin{abstract}
Resistivity geophysical techniques were applied closed to the Londrina's county sanitary landfill, allowing the detection and mapping of leachate contamination plume. The study area lies on the Paraná Basin which is locally represented by basaltic rocks of the Serra Geral Formation.

A correlation between lower resistivity values and the supposed leachate contaminations was stablished, once the electrical conduction, under natural conditions, occurs mainly in an ionic way, which are normally presented in the leachate.

The main contamination flows in a general SE direction. An unexpected finding of this work was the detection of another flux direction of contamination plume to SW, which flows trough horizontal fractures or alteration surfaces of basaltic contacts.
\end{abstract}

Keywords: resistivity, contamination.

RESUMO. Ensaios geofísicos de eletrorresistividade foram efetuados junto ao aterro sanitário do Município de Londrina, permitindo a deteç̧ão e mapeamento da pluma de contaminação pelo chorume. A área de estudo situa-se na Bacia do Paraná, a qual está localmente representada pelas rochas basálticas da Formação Serra Geral.

Estabeleceu-se uma correlação entre os valores mais baixos de resistividade e as possíveis contaminações, uma vez que a condução elétrica, em condições naturais, ocorre principalmente através de íons, que são abundantes no chorume.

0 fluxo da contaminação principal apresenta uma direção geral SE. Uma descoberta inesperada deste trabalho foi a identificação de outra direção do fluxo da pluma de contaminação para SW, a qual flui através de fraturas horizontais ou superfícies de alteração em contatos dos derrames basálticos.

Palavras-chave: resistividade, contaminação.

\footnotetext{
1 Universidade do Vale do Rio dos Sinos - Unisinos, Av. Unisinos, 950 - 93022-000 São Leopoldo, RS - E-mail: jgallas@euler.unisinos.com.br; Tel: (51) 5903333 R-1766; E-mail: ppaim@euler.unisinos.br; Tel: (51) 5903333 R-1743; E-mail: osmar@euler.unisinos.br; Tel: (51) 5903333 R-1738; Fax: (51) 5908177.

2Universidade de São Paulo - USP, Rua do Lago, 562 - 05508-080 São Paulo, SP - E-mail: jgallas@usp.br; Tel: (11) 3091 4232; E-mail: ftaioli@usp.br; Tel: (11) 3091 4200; Fax: (51) 30914207.

3Universidade Estadual de Londrina - UEL, Campus Universitário - 86051-970 Londrina, PR. E-mail: sandra@uel.br; Tel: (43) 3371 4455; Fax: (43) 33284440.
} 


\section{INTRODUÇÃO}

As áreas ambiental e de hidrogeologia têm tido uma crescente demanda de aplicação de geofísica, principalmente quanto ao método da eletrorresistividade.

0 estudo geofísico da área do local de disposição de resíduos sólidos do município de Londrina foi uma das atividades previstas para serem executadas no projeto "Conservação dos recursos hídricos subterrâneos através da definição de metodologia para avaliação da poluição causada pela má disposição de resíduos sólidos urbanos", aprovado pelo CNPq - demanda CTHidro01/2001, processo 550097/2002-3.

Os resultados obtidos com a eletrorresistividade mostraram uma excelente correlação entre a região contaminada e as baixas resistividades. Deve-se isto ao fato de que a condução de corrente elétrica de forma iônica fica favorecida em locais onde os eletrólitos se enriquecem em íons, como é o caso de locais contaminados por chorume.

\section{OBJETIVOS}

Os levantamentos objetivaram detectar anomalias ou assinaturas geofísicas correlacionáveis à pluma de contaminação no subsolo e lençol freático proveniente de contaminação por chorume oriunda do aterro sanitário situado a montante da área estudada.

Os ensaios geofísicos de eletrorresistividade foram realizados na área a jusante do local de disposição de resíduos sólidos do município de Londrina/PR, visando o estabelecer os limites laterais da pluma de contaminação e também uma avaliação de sua penetração em profundidade.

\section{GEOLOGIA DA ÁREA}

0 Município de Londrina/PR situa-se na Bacia do Paraná e, localmente, na área estudada, afloram rochas basálticas da Formação Serra Geral.

A Bacia Sedimentar do Paraná constitui a província estrutural da Plataforma Sul Americana, onde ocorreu a mais extensa manifestação vulcânica de natureza continental na superfície terrestre.

Suas fissuras, fraturas e falhas de distensão permitiram a ascensão de enormes volumes de magma basáltico. A intensidade deste vulcanismo pode ser avaliada pelas dimensões de diques que podem atingir mais de $100 \mathrm{~km}$ de extensão e até centenas de metros de espessura (Almeida et al., 1976).

0 tectonismo responsável pelo fraturamento da crosta e ascensão de grandes volumes de magma, na era mesozóica da Bacia do Paraná, está intimamente associado à fragmentação do antigo mega-continente Gondwana.

Especificamente, na região de Londrina, estima-se que a espessura dos derrames basálticos situe-se entre 600 e $800 \mathrm{~m}$.

\section{CONTAMINAÇÕES E RESISTIVIDADE}

A condução da corrente elétrica na natureza processa-se principalmente da forma iônica, sendo este modo de condução o mais significativo nos estudos por eletrorresistividade.

As pseudo-seções e seções modeladas de resistividade evidenciam claramente a relação deste parâmetro com a pluma de contaminação ao longo dos perfis ensaiados.

As contaminações em subsuperfície são os locais em que as resistividades apresentam-se mais baixas porque, devido à presença dos contaminantes, estes locais têm aumentado consideravelmente seu conteúdo iônico. Desta forma, aí a corrente se propagará com maior facilidade, resultando em zonas menos resistivas. Este comportamento obedece à lei de $0 \mathrm{hm}$,

$$
\vec{J}=\sigma \vec{E}
$$

onde $J$ é a densidade de corrente, $E$ o campo elétrico e $\sigma$ a condutividade do meio.

Uma vez que a grande maioria das rochas e o subsolo em geral são maus condutores, suas resistividades deveriam ser extremamente altas não fosse pelo fato que usualmente os poros estão preenchidos por fluidos, principalmente água. Em vista disso, assumem um comportamento de condutores eletrolíticos (Telford et al., 1990), cuja resistividade aparente pode ser definida como na conhecida e simples equação 2 adiante, derivada da Lei de $0 \mathrm{hm}$.

A resistividade é obtida pela emissão de uma corrente $I$, emitida através de dois eletrodos $A$ e $B$ e a diferença de potencial $\Delta V$, usualmente medida através dos eletrodos de potencial ditos $M$ e $N$. A partir destes parâmetros é possível obter-se a resistividade aparente $\rho_{a}$. Em um terreno homogêneo e isotrópico esta resistividade será constante para quaisquer disposições de eletrodos que sejam empregadas nas medições.

$$
\begin{gathered}
\rho_{a}=K \frac{\Delta V}{I} \\
K=\frac{2 \pi}{\frac{1}{A M}-\frac{1}{B M}-\frac{1}{A N}+\frac{1}{B N}}
\end{gathered}
$$

onde $K$ é um fator geométrico que depende das distâncias entre os eletrodos de corrente $(A$ e $B)$ e de potencial $(M$ e $N)$, $I$ é a corrente gerada entre os eletrodos de corrente e $\Delta V$ a diferença de potencial estabelecida entre $M$ e $N$.

As resistividades também variam com a mobilidade, concentração e grau de dissolução dos íons, sendo que o grau de 
dissolução depende da constante dielétrica da solução. Comparativamente à condução ôhmica (eletrônica), a condução iônica não é tão somente mais lenta, mas representa também um transporte de material (Keller \& Frischknecht, 1977).

A resistividade de uma rocha decresce com o aumento de seu conteúdo de água e também com o volume dissolvido de cloretos, sulfatos (sais em geral) e presença de outros minerais. Além disto, para haver boa condução elétrica os poros precisam estar interligados e preenchidos com água.

No sentido de correlacionar-se resistividade com conteúdo de água, foi observado que a resistividade varia aproximadamente com 0 inverso do quadrado da porosidade, quando a rocha está saturada com água. Esta observação levou ao uso difundido de uma relação empírica de resistividade e porosidade (Archie, 1942), conhecida como Lei de Archie.

$$
\rho=a \rho_{w} \varphi^{-m}
$$

onde $\rho$ é a resistividade total, $\rho_{w}$ a resistividade da água dos poros, $\phi$ é a porosidade expressa como uma fração por unidade de volume e $a$ e $m$ referem-se ao tipo de porosidade e grau de cimentação, respectivamente.

\section{TÉCNICAS UTILIZADAS E ENSAIOS EFETUADOS}

Os levantamentos de eletrorresistividade executados consistiram de seis perfis - Linhas A, B, C, D, E e F - com 0 arranjo dipolodipolo com aberturas $A B=M N=20 m$ e cinco níveis teóricos de investigação ( $n 1=20 \mathrm{~m} ; \mathrm{n} 2=30 \mathrm{~m} ; \mathrm{n} 3=40 \mathrm{~m} ; \mathrm{n} 4=50 \mathrm{~m}$ e n5 = $60 \mathrm{~m}$ ), respectivamente (Hallof, 1957). A opção pelo dispositivo dipolo-dipolo deveu-se aos objetivos a serem alcançados pela geofísica, quais sejam, a determinação dos limites da pluma de contaminação do chorume, bem como indicações do comportamento da poluição com a profundidade.

A separação entre perfis foi determinada no campo através de posicionamento com GPS e foram praticamente paralelos entre si. As posições das linhas podem ser vistas na Figura 1 que contém o mapa de resistividade. Os perfis foram efetuados perpendicularmente à drenagem existente visando interceptar a zona contaminada.

Também são apresentadas as seções modeladas através de processos de inversão de dados, por meio do programa RES2DINV da ABEM Instruments (ABEM, 1998, Loke \& Barker, 1995), cujas profundidades de investigação fundamentam-se em Edwards (1977) e são aproximadamente a metade daquelas propostas por Hallof (op. cit.).

Estão sendo apresentados neste trabalho os resultados dos perfis C e D e o mapas de resistividade dos níveis de investigação

\section{2 e 4 e a simulação 3-D referente ao nível 4.}

\section{PROCESSAMENTO E ANÁLISE DOS RESULTADOS}

Medidas de resistividade normalmente são apresentadas e interpoladas (contornos de isovalores) sob a forma de pseudoseções (Hallof, 1957) que dão uma representação visual do comportamento das resistividades em subsuperfície. No entanto, as formas dos contornos não dependem exclusivamente das distribuições de resistividades medidas, mas também da geometria da configuração de eletrodos empregada. Mesmo corpos de formas geométricas simples (retangulares, p. ex.), apresentam pseudo-seções completamente diferentes, conforme 0 arranjo empregado.

Nesse sentido, para obter-se uma seção de resistividade mais precisa, torna-se necessária a aplicação de processos de inversão nos dados que, em tese, conduz a uma aproximação razoável de modelos para diversas estruturas geológicas.

As seções modeladas são resultantes de um processo automático de inversão bi-dimensional (2-D). Os processos de inversão de dados de resistividade buscam estabelecer um modelo da provável distribuição real dos valores de resistividade em subsuperfície. As eventuais distorções nas pseudo-seções inerentes aos arranjos de eletrodos são, teoricamente, eliminadas por este procedimento.

Os dados obtidos foram processados através dos programas RES2DINV e Surfer 8, da ABEM Instruments (1998) e Golden Software, respectivamente. 0 Surfer 8 é um programa para interpolação de dados, enquanto que o RES2DINV é um programa de inversão para resistividade e polarização induzida (IP).

Os resultados da inversão pelo RES2DINV foram exportados na forma de arquivos XYZ e interpolados pelo Surfer 8 (krigagem), visando uma apresentação de melhor qualidade dos mesmos.

0 RES2DINV adota uma técnica rápida e eficiente para inversão de dados de resistividade que foi desenvolvida por Loke \& Barker (1996a, 1996b) e deGroot-Hedlin \& Constable (1990), baseia-se no método dos mínimos quadrados e "suavização restringida" (smoothness-constrained). Teoricamente, produz um modelo de subsuperfície 2-D isento das distorções na pseudoseção de resistividade aparente originadas pela geometria do arranjo eletródico usado.

\section{INTERPRETAÇÃO}

As Figuras 4 e 5 , trazem as pseudo-seções de resistividade aparente e seções modeladas de resistividade dos perfis $\mathrm{C}$ e $\mathrm{D}$. Ambas as formas de apresentação dos dados mostram contras- 


\section{ATERRO SANITÁRIO MUNICIPAL - LONDRINA/PR MAPA DE RESISTIVIDADE PLOTAGEM DO NÍVEL 2 DO DIPOLO-DIPOLO}

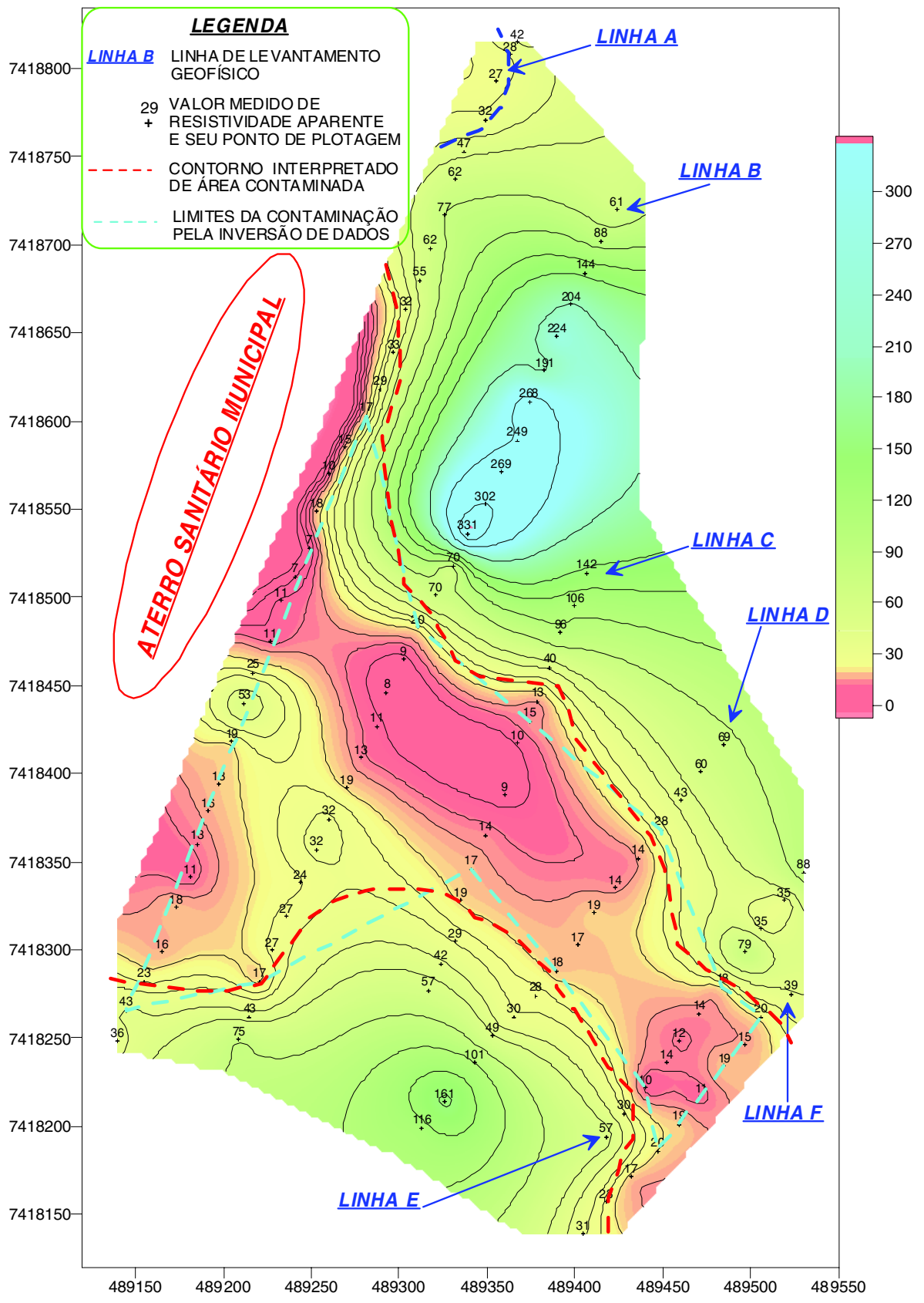

Figura 1 - Mapa de resistividade, nível 2 do dipolo-dipolo.

tes de resistividade bastante nítidos. É possível estabelecer-se uma correlação entre as zonas de resistividades mais baixas e a contaminação por chorume. Esta associação é a normalmente esperada, uma vez que o chorume é riquíssimo em íons e a condução da corrente elétrica em condições como as existentes na natureza dá-se principalmente de forma iônica. Desta forma, os substratos com um eletrólito rico em íons permitirão que a corrente elétrica se propague com maior facilidade, resultando em 


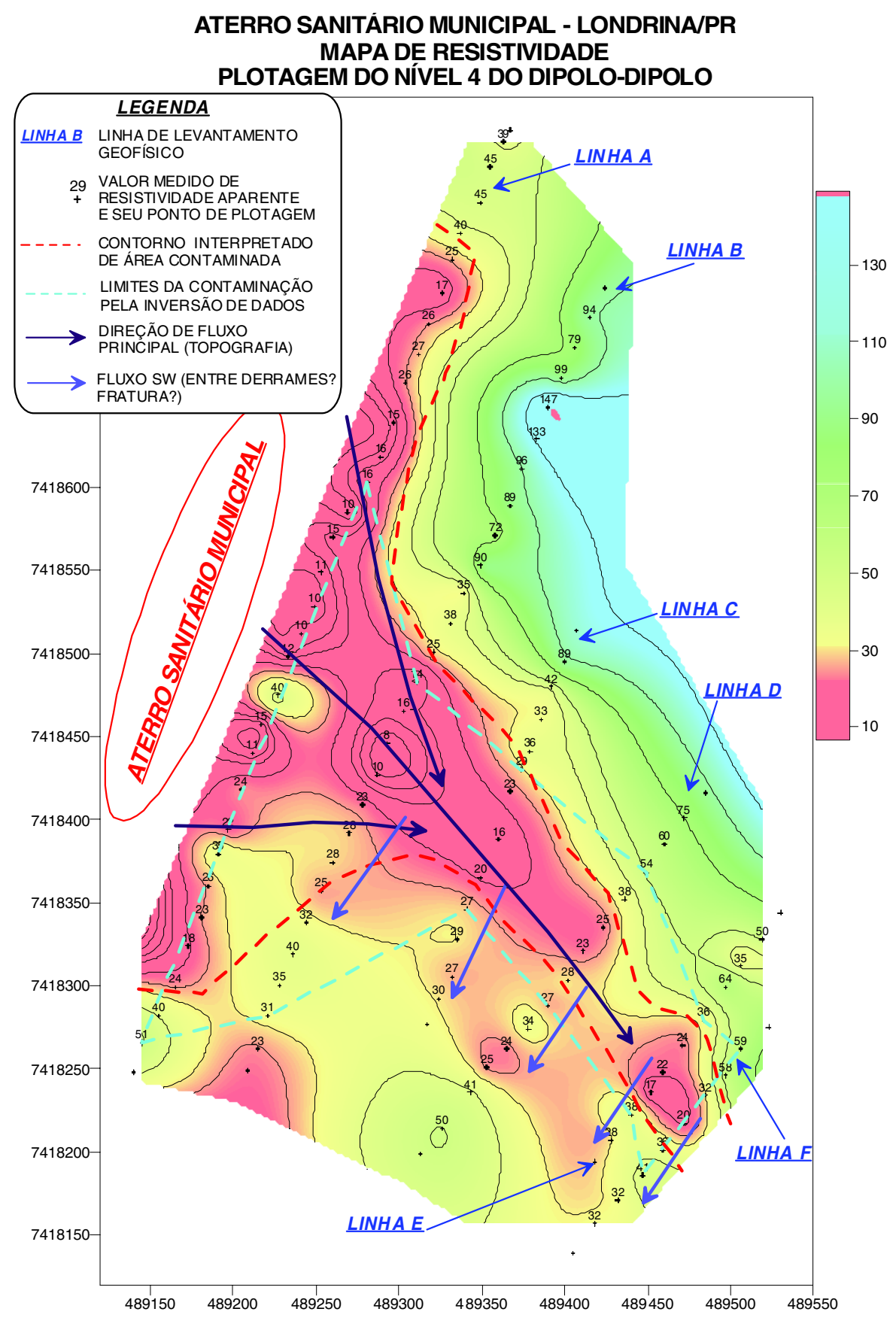

Figura 2 - Mapa de resistividade, nível 4 do dipolo-dipolo.

anomalias de baixas resistividades.

Por outro lado, regiões de basaltos, como é o caso da área estudada, costumam apresentar solos e níveis superficiais da rocha alterada/fraturada com baixas resistividades. Mesmo assim, em tal situação, a resistividade decrescerá como um todo e o que se busca são os contrastes relativos de resistividade entre o substrato contaminado e o não contaminado.

Outro fato a ser lembrado é que a área em questão situa-se em uma drenagem para onde fluem as águas de subsuperfície, 0 que também ocasiona uma queda nos padrões de resistividade. 
Conforme visto nas Figuras 4 e 5, são assinaladas nas mesmas, através de uma barra hachurada, as projeções na superfície das regiões consideradas associadas à contaminação, assim interpretadas de acordo com as características apresentadas pelas resistividades - baixas - nestas associações com chorume. Este padrão é representado nas seções modeladas e pseudo-seções através da cor avermelhada.

De forma a ter-se uma visualização em planta da extensão da região interpretada como atingida pelo chorume, foram elaborados mapas de resistividade, gerados a partir dos dados do dipolodipolo e apresentados nas Figuras 1 e 2. Com o mesmo objetivo, foi também elaborada uma simulação tri-dimensional do mapa de resistividade aparente do nível 4 e está sendo apresentada na Figura 3.

0 mapa apresentado na Figura 1 contém os dados de resistividade do nível 2 (cerca de 14m, segundo Edwards, 1977) das pseudo-seções de resistividade aparente. Verifica-se uma distribuição dos valores mais baixos de resistividade que originase a montante da área, abrangendo grande parte da linha A, situada mais próxima do aterro, e prolonga-se até a linha mais a jusante - linha F, estreitando-se nesta direção. A linha F situa-se na porção da drenagem onde já há água aflorante, nascente do riacho.

Os limites da área interpretada como contaminada pelo chorume foram assinalados com uma linha tracejada vermelha. Igualmente foi assinalado um polígono com linha tracejada em azul na área geometricamente delimitada pelos dados de resistividade submetidos aos processos de inversão. Constata-se que a interpretação qualitativa visual e a fornecida pela inversão dos dados apresenta uma excelente correlação.

Para avaliar-se semi-quantitativamente 0 comportamento da contaminação em um nível mais profundo, foi elaborado um mapa de resistividade com os valores referentes ao nível 4 de investigação (cerca de 24 m, segundo Edwards, 1977). Foi delimitada neste mapa com uma linha tracejada em vermelho a interpretação da área contaminada neste nível mais profundo. Observa-se que a pluma de contaminação apresenta-se um pouco mais estreita que no mapa anterior. Foi assinalado por meio de setas neste a possível existência de uma outra direção do fluxo de contaminação, conforme descrito a seguir.

As seções modeladas e pseudo-seções indicam que a contaminação, além da direção SE, deve estar se propagando em profundidade também na direção SW, conforme pode ser visto e assinalado nas seções modeladas, principalmente das linhas $C$, D, E e F. Interpreta-se que esta percolação acontece ao longo de fratura(s) horizontalizadas ou ao longo da superfície de alteração que comumente ocorre entre dois derrames basálticos.

Dados de 12 sondagens efetuadas na área estudada mostram que a profundidade do topo rochoso é rasa e situa-se entre 4 e $11 \mathrm{~m}$ de profundidade, 0 que dá sustentabilidade a esta interpretação. Uma vez que a espessura dos derrames basálticos é bastante variável (poucos a vários metros), então é perfeitamente razoável a interpretação de um contato entre derrames na profundidade indicada nas seções modeladas de resistividade (figuras 4 e 5) onde ocorre a infiltração SW interpretada.

\section{CONCLUSÕES E RECOMENDAÇÕES}

De acordo com o objetivo proposto, considera-se que os ensaios geofísicos realizados na área do aterro sanitário do município de Londrina atingiram plenamente o mesmo, qual seja 0 de mapear a área atingida pela pluma de contaminação do chorume. 0 recobrimento da área estudada foi pleno, uma vez que os trabalhos se realizaram desde um perfil (linha A) situado imediatamente adjacente ao aterro e estendeu-se até onde começa a surgir água na drenagem (entre linhas $\mathrm{E}$ e F).

0 método da eletrorresistividade é uma técnica geofísica de prospecção indireta, devendo os resultados e interpretações aqui apresentados serem usados para a otimização das investigações diretas subseqüentes, tais como sondagens/poços de monitoramento, aberturas de valas, trincheiras etc.

Uma vez que a maior condução elétrica em condições naturais dá-se principalmente através de íons, nos quais o chorume é bastante rico, interpretou-se uma correlação entre os valores medidos de resistividades mais baixas e as possíveis contaminações por chorume.

De acordo com estes critérios, recomenda-se como metodologia de detecção direta da área atingida pela pluma de contaminação, sondagens/poços de monitoramento na área indicada como contaminada na figura 1 - mapa de resistividade do nível 2. Também são recomendadas sondagens/poços de monitoramento externamente à área contaminada a título de confirmar-se as zonas não atingidas.

Complementarmente, podem ser realizados testes/ensaios de permeabilidade nas sondagens futuras, possibilitando uma estimativa de estabelecer-se a velocidade dos fluxos subterrâneos na área estudada.

0 fluxo da contaminação principal apresenta uma direção geral SE. Uma descoberta inesperada deste trabalho foi a identificação de outra direção do fluxo da pluma de contaminação para SW, a qual flui através de fratura(s) horizontal(is) ou superfícies de alteração em contatos dos derrames basálticos. 


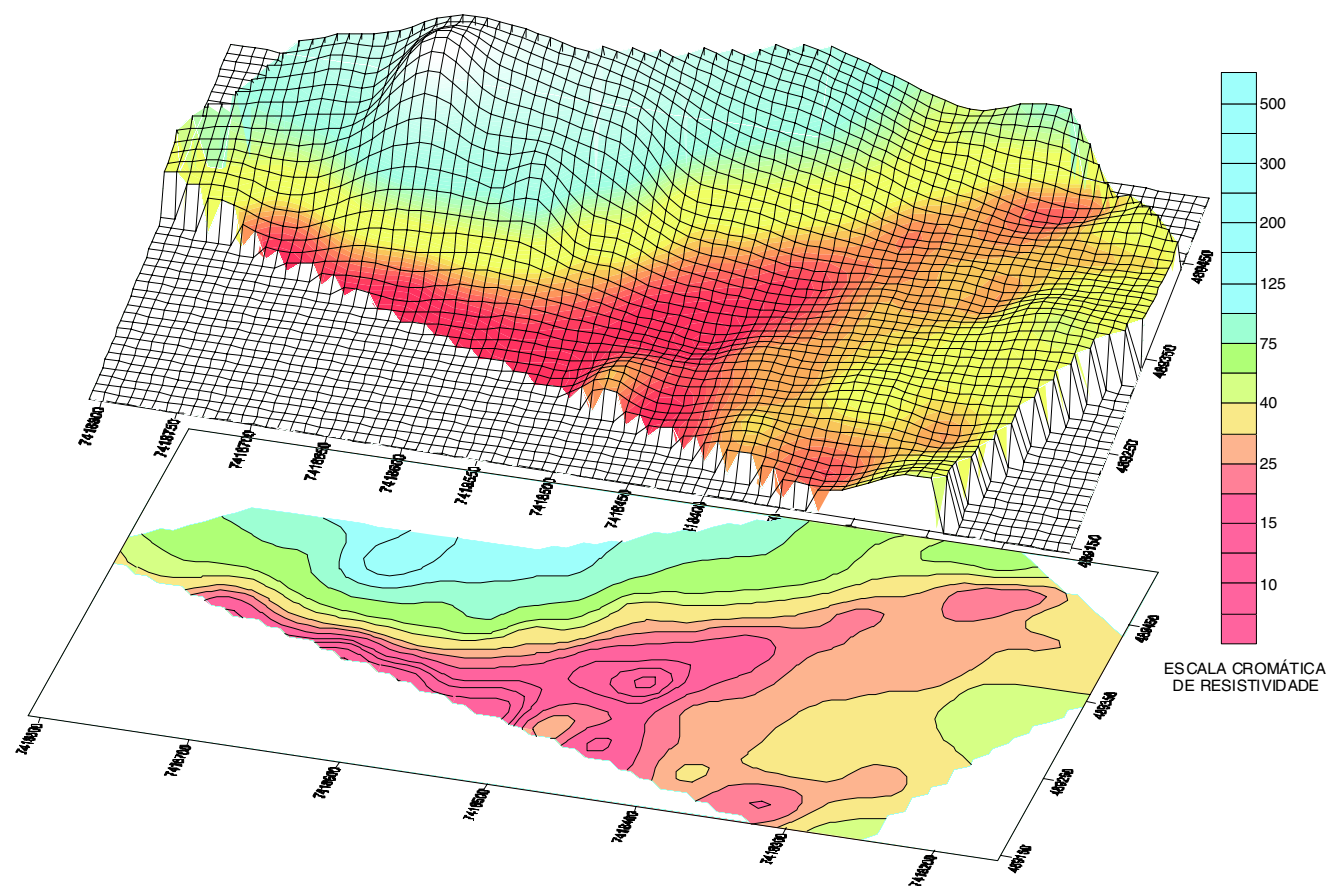

Figura 3 - Bloco 3D e mapa de resistividade, nível 4 do dipolo-dipolo.

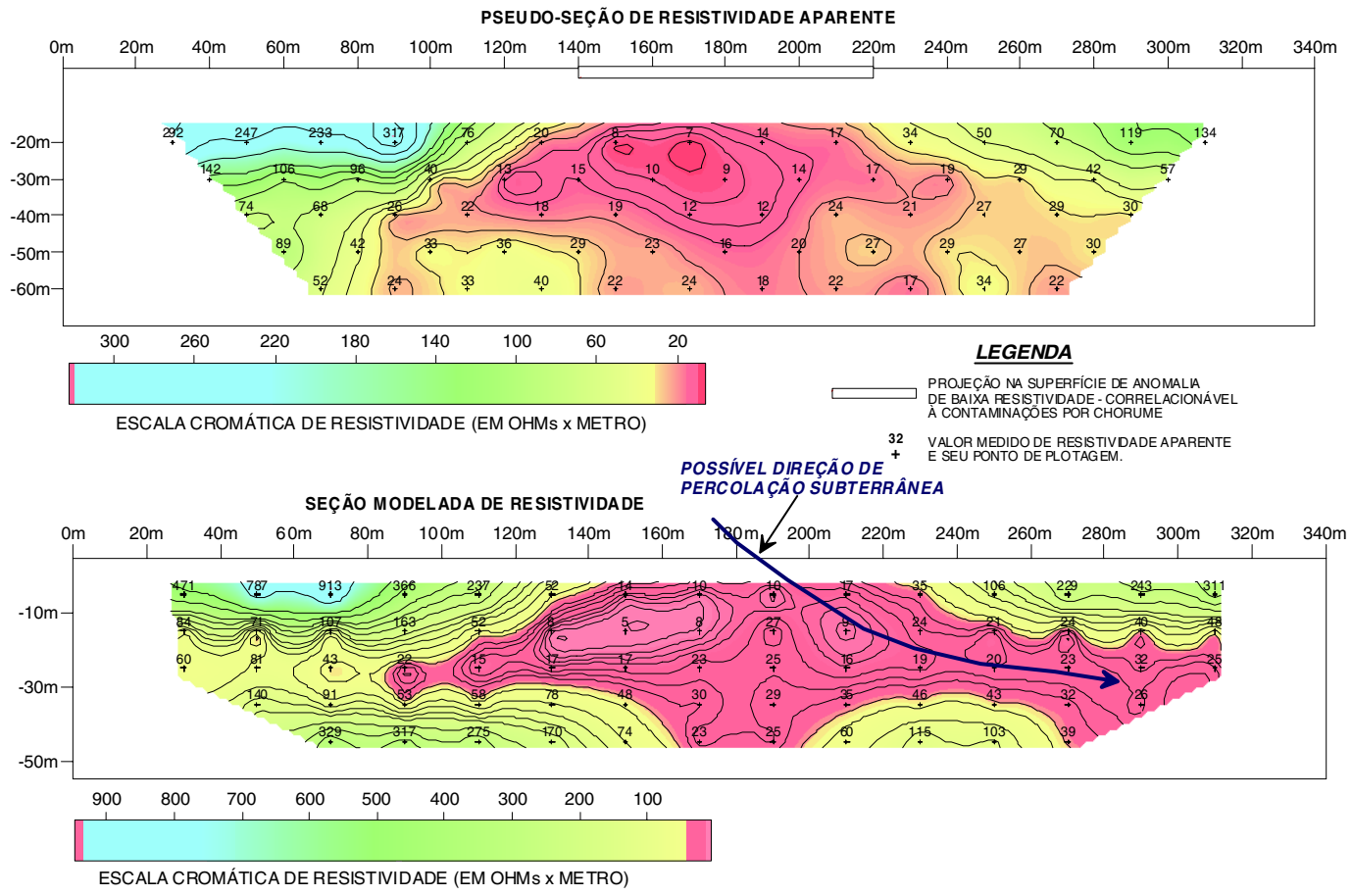

Figura 4 - Pseudo-seção e seção modelada de resistividade, Linha C. 

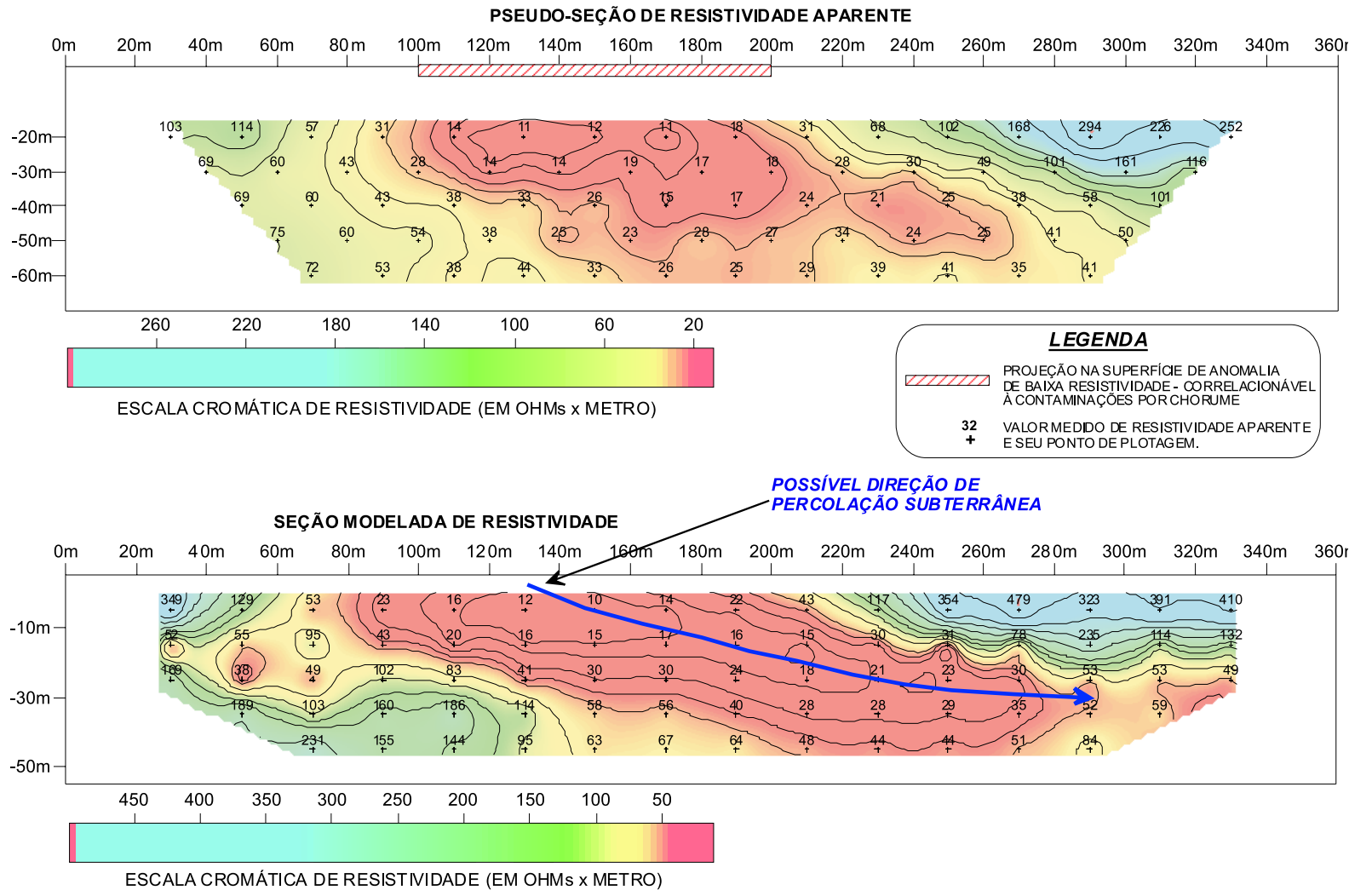

Figura 5 - Pseudo-seção e seção modelada de resistividade, Linha D.

Esta interpretação sustenta-se no fato de que as espessuras do manto de alteração na área onde os ensaios foram efetuados oscila entre 4 e 11m, de acordo com os dados de 12 sondagens realizadas no local. Sabendo-se que os derrames basálticos têm espessuras muito variáveis, então pode-se admitir uma interface entre derrames na profundidade indicada para a infiltração SW, conforme assinalado nas seções modeladas de resistividade. A confirmação desta hipótese depende de execução de sondagens locadas baseando-se nas indicaçõs das figuras 2 (mapa do nível 4) e nas seções modeladas de resistividade (Figuras 4 e 5).

\section{AGRADECIMENTOS}

Este trabalho foi realizado graças ao apoio do CNPq, via Projeto "Conservação dos recursos hídricos subterrâneos através da definição de metodologia para avaliação da poluição causada pela má disposição de resíduos sólidos urbanos", aprovado pelo CNPq - demanda CT-Hidr001/2001, processo 550097/20023. Agradece-se também aos revisores, que contribuíram para 0 aperfeiçoamento da apresentação final deste trabalho.

\section{REFERÊNCIAS}

ABEM INSTRUMENTS. 1998. Geoelectrical Imaging 2D \& 3D RES2DINV, ver. 3.3 for Windows 3.1, 95 and NT. Rapid 2D Resistivity \& IP inversion using the least-squares method. By M. H. Loke. ABEM Instruments, P.0. Box 20086, S-161 02 Bromma, Sweden. Paginação irregular.

ALMEIDA FFM, HASUI Y \& NEVES BBB. 1976. The upper precambrian of South America. São Paulo, Instituto de Geociências, Universidade de São Paulo, São Paulo. Boletim 7, p. 45-80.

ARCHIE GE. 1942. The electrical resistivity log as an aid in determining some reservoir characteristics. Trans. A.I.M.E. 146: 54-64.

deGROOT-HEDLIN C \& CONSTABLE S. 1990. Occam's inversion to generate smooth, two-dimensional models form magnetotelluric data. Geophysics, 55(12): 1613-1624.

EDWARDS LS. 1977. A modified pseudo-section for resistivity and induced-polarization. Geophysics, 3: 78-95.

HALLOF PG. 1957. On the interpretation of resistivity and induced polarization measurements: Cambridge, MIT, Ph. D. thesis.

KELLER GV \& FRISCHKNECHT FC. 1977. Electrical methods in geophysical prospecting. Oxford: Pergamon Press, 517 p. 
LOKE MH \& BARKER RD. 1995. Least-squares deconvolution of apparent resistivity pseudosections. Geophysics, 60(6): 1682-1690.

LOKE MH \& BARKER RD. 1996a. Rapid least-squares inversion of apparent resistivity pseudosections by a quasi-Newton method. Geophysical Prospecting, 44: 131-152.

LOKE MH \& BARKER RD. 1996b. Practical techniques for 3D resistivity surveys and data inversion. Geophysical Prospecting, 44: 499-523.

ORELLANA E. 1972. Prospeccion geoeletrica en corriente continua. Madrid: Paraninfo, $523 \mathrm{p}$.

TELFORD WM, GELDART LP \& SHERIFF RE. 1990. Applied geophysics. Second Edition. Cambridge: Cambridge University Press, $770 \mathrm{p}$.

\section{NOTAS SOBRE OS AUTORES}

José Domingos Faraco Gallas. Bacharelou-se em Geologia pela Universidade Federal do Rio Grande do Sul em 1978. Concluiu mestrado em Geofísica em 1990 pela Universidade Federal do Pará. Doutorou-se em Geociências e Meio Ambiente, ênfase em Geofísica Aplicada pela UNESP - Universidade Estadual Paulista em 2000. Foi Pesquisador do Instituto de Pesquisas Tecnológicas do Estado de São Paulo - IPT de 1979 até início de 2002. Atualmente é Prof. Doutor do Instituto de Geociências da Universidade de São Paulo - USP (licenciado) e Prof. Adjunto II da Universidade do Vale do Rio dos Sinos - Unisinos. Áreas de interesse: geofísica aplicada à prospecção mineral, hidrogeologia, geologia de engenharia e geologia ambiental.

Fabio Taioli. Formou-se em Geologia pela USP em 1973. Foi geofísico da Petrobrás até 1975 quando transferiu-se para o Instituto de Pesquisas Tecnológicas do Estado de são Paulo - IPT. Obteve, em 1987, seu MSc em Mining Engineering pela The Pennsylvania State University na área de Geomecânica. Doutorou-se pelo Instituto de Geociências da USP em 1992 na área de Geofísica Aplicada. Transferiu-se para o IG-USP em 1995 onde é Professor Associado. Sua área de interesse é a aplicação de métodos geofísicos a problemas de engenharia civil e de minas e meio ambiente. É membro da SBGf, SEG, EEGS, IAEG, ISRM, ABGE, ABMS, CBMR.

Sandra Márcia Cesário Pereira da Silva. Engenheira civil pela Universidade Estadual de Londrina em 1979. Concluiu mestrado em Hidráulica e Saneamento em 1984 pela Escola de Engenharia de São Carlo - USP. Doutorou-se em Engenharia Civil, ênfase em saneamento pela Escola Politécnica - USP em 1993. Concluiu pós doutorado na Escola Politécnica - USP em saneamento em 2001. Professora doutora da Universidade Estadual de Londrina desde 1980, atuando na área de hidráulica e saneamento e coordenadora do programa de mestrado em Engenharia de Edificações e saneamento. Áreas de interesse: tratamento de águas residuárias, gestão de resíduos sólidos urbanos, poluição de recursos hídricos e áreas contaminadas.

Osmar Gustavo WöhI Coelho. Bacharelou-se em Geologia pela Universidade Federal do Rio Grande do Sul (UFRGS) em 1977. Mestre em Ciência do Solo em 1992 pela UFRGS. Doutor em Ciência do Solo pela UFRGS / ITC - International Institute for Aerospace Survey and Earth Science - The Nethterlands. Em 1978 trabalhou como geólogo PETROBRÁS. Nos períodos de 1978-984 e 1986-994, trabalhou como geólogo de engenharia em empresas de consultoria e projetos. De 1984 a 1986 atuou como Analista de Sistemas do SERPRO na área de processamento de imagens de Satélite, atuando em conjunto com o INPE. Desde 1992 é professor adjunto II da UNISINOS. Áreas de interesse: geotecnia, geofísica, hidrogeologia e geoprocessamento.

Paulo Sergio Gomes Paim. Bacharel em Geologia (1978) e Mestre em Geociências (1983), ênfase em petrologia orgânica, pela Universidade Federal do Rio Grande do Sul. Geólogo da Universidade Federal do Rio Grande do Sul (1981 a 1983), atuando nas áreas de estratigrafia, sedimentologia e geologia do carvão. Professor adjunto da Fundação Universidade do Rio Grande (1983 a 1986), atuando na área de oceanografia geológica. Doutor em Filosofia pela University of Oxford (Inglaterra), em 1994, na área de sedimentologia. Desde 1986 trabalha na Universidade do Vale do Rio dos Sinos, onde atualmente é professor titular, atuando na área de Geociências. Áreas de interesse: Estratigrafia, Sedimentologia, Geologia do Petróleo e Geofísica. 